\title{
Model-based Insulin-Nutrition Administration for Glycaemic Control in Malaysian Critical Care: First Pilot Trial
}

\author{
A. Abu-Samah ${ }^{1}$, N.H. Ahamad ${ }^{1}$, N.N. Razak ${ }^{1}$, F.M. Suhaimi ${ }^{2}$, U.K. \\ Jamaludin $^{3}$, A.M. Ralib ${ }^{4}$, M.B. Mat-Nor ${ }^{4}$ J.L. Dickson ${ }^{5}$ C.G. Pretty ${ }^{5}$, and \\ Geoffrey Chase ${ }^{5}$ \\ 1 Department of Electronics \& Communication Engineering, College of Engineering, \\ Universiti Tenaga Nasional Malaysia \\ 2 Advanced Medical and Dental Institute, Universiti Sains Malaysia \\ 3 Faculty of Mechanical, Universiti Malaysia Pahang \\ 4 Kuliyyah of Medicine, International Islamic University Malaysia \\ 5 Department of Mechanical Engineering, University of Canterbury, New Zealand \\ Asma@uniten.edu.my
}

\begin{abstract}
Stress-induced hyperglycemia is prevalent in critical care, even in patients with no history of diabetes. Control of blood glucose level with tight insulin therapy has been shown to reduce incidences of hyperglycemia leading to reduced mortality and improved clinical outcomes. STAR is a tablet-based glucose control protocol with a specialized user interface into which insulin and nutrition information can be entered and predicted. This research describes the first clinical pilot trial of STAR approach in International Islamic University Hospital, Kuantan, Pahang. The clinically specified target for blood glucose level is between 4.4 and $8.0 \mathrm{mmol} / \mathrm{L}$. Seven episodes (359 hours) were recruited based on the need for GC. Overall, $43.93 \%$ of measurement are in the range of 4.4-8.0 mmol/L band. The BG median is 8.30 [6.32 - 10.00] $\mathrm{mmol} / \mathrm{L}$ with only 1 patient having below than $2.22 \mathrm{mmol} / \mathrm{L}$ which is the guaranteed minimum risk level. This pilot study shows that STAR protocol is a patient specific approach that provides a good glycemic control in critically ill patients. Nevertheless, its implementation in Malaysian intensive care environments require modifications and improvements in certain areas.
\end{abstract}

Keywords: Glycemic Control; Model-Based Approach; Hyperglycemia; Critical Care; Clinical Trial.

\section{Introduction}

Stress-induced hyperglycemia is common in critically ill patients, even among those without diabetes mellitus [1/2 3/4. The metabolic response to stress is characterized by major changes in glucose metabolism. Hyperglycemia is not only a marker for severity of illness, it also worsens outcomes, leading to an 
increased risk of further complications, such as severe infections [5], myocardial infarctions [6], polyneuropathy and multiple-organ failure [3. Glucose Control (GC) has been shown to reduce intensive care unit (ICU) patient mortality up to $45 \%[3 / 7 / 8 \mid 9$. However, other GC studies have shown the difficulty in reproducing the reduced risk of death in patients [1011/12]. A recent study showing glycemic outcome is a function of GC given and not of patient condition 13 has reopened debate on GC and how to apply it safely and effectively.

The Stochastic TARgeted (STAR) protocol is based on a clinically validated model [14]15] to provide specific recommendations for insulin, as well as nutrition, while controlling hyperglycemia and ensuring a maximum of $5 \%$ of the risk of light hypoglycemia [16/17. STAR is an adaptable model-based control approach that empowers versatile, patient-specific GC. It is applied over a range of clinical conditions and is used for real-time bedside care. Since 2010, two hospitals have been using STAR protocol as standard of care for GC in their ICUs namely Christchurch hospital, New Zealand and Kálmán Pándy Hospital, Hungary.

This paper presents a STAR protocol modulating only insulin infusions toward a targeted glycemia range of 4.4 to $8.0 \mathrm{mmol} / \mathrm{L}$. The initial pilot trial results of the protocol are compared with the simulations using the same patients data. This pilot trial tests the ability to adapt the model-based STAR GC framework from its development environment at Christchurch Hospital in New Zealand to the International Islamic University Malaysia (IIUM) Hospital ICU which has an ethnically different cohort and culturally different clinical practice.

\section{Method}

\subsection{STAR Protocol}

STAR uses a time varying insulin sensitivity to capture changes in patient condition and insulin-nutrition metabolism over time. Starting criteria for STAR is two BG measurements over $8 \mathrm{mmol} / \mathrm{L}$ within a 4 -hour period. The benchmarked BG target range of STAR is set at $4.4-8.0 \mathrm{mmol} / \mathrm{L}$ based on reduced risks with inreased BG in intermediate bands. STAR specifically captures developing physiological patient condition and inter- and intra-patient fluctuation by identifying insulin sensitivity (SI) and its future variabillity to optimize safety and GC performance. Its elements can be modified according to clinically determined glycemic targets, control approaches (e.g. insulin only, insulin and nutrition, etc.) and clinical resources (e.g. measurement frequency).

STAR is implemented in tablet computer to provide specialized user interface into which nutrition and insulin information can be entered. Once BG measurements are taken, an insulin sensitivity profile can be computed. Insulin sensitivity varies hourly, and stochastic based forecasting is used to determine likely outcomes in insulin sensitivity for any possible insulin and/or nutrition input. This forecasting allows changes in future insulin sensitivity to be determined.

The insulin-nutrition combination that best overlaps the resulting $\mathrm{BG}$ range with the target clinical band is selected by placing the 5th percentile BG out- 
come on the lower edge of the clinically specified target range. STAR seeks to maximize nutrition delivery while dosing insulin in this context. If, for maximum nutritional and insulin treatments, the BG outcome range does not sufficiently overlap the clinical target range, then STAR will recommend a drop in nutrition to maintain GC and reduce risk [17. The nutrition will be raised back to its goal feed value as soon as possible. In cases where the feed must be clinically determined or switched off, STAR can be set to give insulin recommendations only. Figure 1 summarizes how STAR functions.

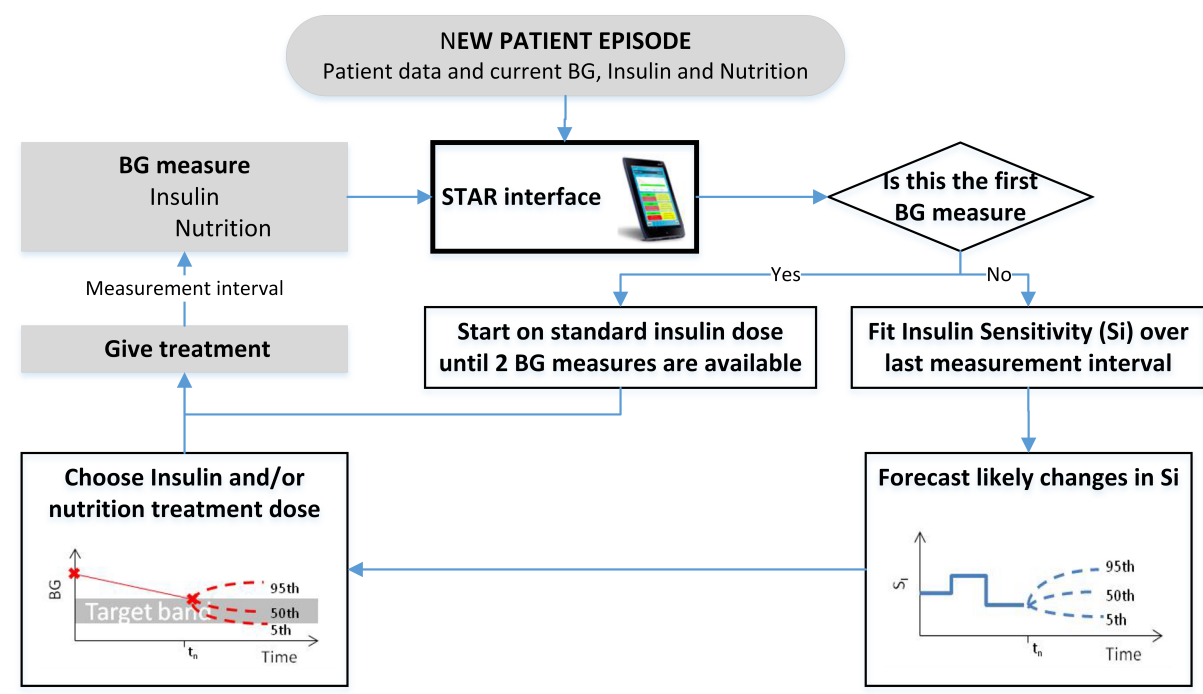

Fig. 1: Summary of the STAR functions. SI is the insulin sensitivity, BG is blood glucose.

\section{$2.2 \quad$ Pilot Trial}

In this first pilot trial for Malaysian critically ill patients, seven episodes (of 359 hours) from four non-diabetic patients was controlled using STAR. These were obtained during their ICU stay in the first semester of 2017. Patient 1 and 2 had more than one episodes as they were taken off GC using STAR tablet due to judgement by medical staffs who were new to its use. The selection criteria includes GC for a minimum of 24 hours. Table 1 shows the baseline for each episode (age, sex, hours, initial BG and diagnosis). Written informed consent was obtained for all patients, and approval (IREC 657) was granted for this study by IIUM Research Ethics Committee and National Institute of Health (NIH). 
Table 1: Baseline clinical data of all four patients and corresponding to seven episodes.

\begin{tabular}{|l|l|l|l|l|l|}
\hline Patient & Age & Sex & Hours & Initial BG & Diagnosis \\
\hline 1a & 56 & F & 58 & 14.4 & Congestive Heart Failure, Lung Fibrosis Mixed Connective Tissue Disease, \\
\cline { 1 - 4 } 1b & 56 & F & 46 & 10.2 & Acute Pulmonary Oedema, Billateral Parenchymal Disease \\
\hline 21 & 49 & M & 71 & 11.0 & \multirow{2}{*}{ Motor Vehicle Accident with Polytrauma Hyper Tension } \\
\hline 2b & 49 & M & 28 & 11.6 & \\
\hline 2c & 49 & M & 85 & 11.7 & $\begin{array}{l}\text { Early Glottic CA, Left vocal Cord, Heart Disease Hyper Tension, } \\
\text { Diabetes Mellitus }\end{array}$ \\
\hline 3 & 70 & M & 33 & 17.4 & Hospital required Pneumonia, Renal Cell Carcinoma with Brain Metastasis \\
\hline 4 & 66 & F & 38 & 11.8 &
\end{tabular}

For each patient, the trial started with a BG measurement made by nursing staff. BG measurements were made using B-Braun glucometers. The approach then identifies a new insulin and nutrition infusion rate, which was then given by the nurse. The time interval until the next BG measurement is also selected by the medical staffs based on 1-3 hourly treatment options offered.

\subsection{Virtual Trial}

To analyze the compliance of STAR as clinically applied GC protocol, a virtual trial was conducted using the clinical data. This trial has two phases: i) Fitting and ii) Simulation. During the fitting, clinical data were used to identify hourly SI values which served as a virtual patient profile. This profile reflects the glycemic response to insulin and nutrition inputs and can be used to simulate responses to different interventions with good accuracy 15/18. In the second phase, the profile was used to simulate glycemic response to STAR as simulated, where differences indicates non-compliance to STAR.

\section{Results}

Clinical results are summarized by whole cohort statistics in Table2 2 There were 239 BG measurements taken during 359 hours of control. BG median value, 8.3 $\mathrm{mmol} / \mathrm{L}$ for whole cohort is higher than BG target of $8.0 \mathrm{mmol} / \mathrm{L}$. BG levels are relatively widely distributed, as evidenced by the IQR range (25th-75th percentile value) of $4.68 \mathrm{mmol} / \mathrm{L}$ for the cohort, and the $25-75 \%$ confidence interval across patients in Figure 2. Table 2 shows that $43.93 \%$ of BG measurements are between 4.4 to $8.0 \mathrm{mmol} / \mathrm{L}$. The control is tight in this band, as illustrated by the steep slope of BG Cumulative Distributive Function (CDF) for the whole cohort in Figure 2 and similar per-patient CDFs. There was only one patient with severe hypoglycemic (measurement $\mathrm{BG}<2.22 \mathrm{mmol} / \mathrm{L}$ ) which was patient $2 \mathrm{~b}$.

Virtual trial results are also presented in Table 2 The total number of BG measurements is significantly reduced by 36 , from an average 16 per-day to the 13 per-day that matches STAR in use else where [19]. Overall statistics for BG measurements recorded better numbers than clinical results. $66.50 \%$ patients are 
between target range of 4.4 to $8.0 \mathrm{mmol} / \mathrm{L}$ and only $7.88 \%$ of patients with $\mathrm{BG}$ $>10.0 \mathrm{mmol} / \mathrm{L}$. There is no episode of severe hypoglycemia.

Table 2: Cohort blood glucose results based on clinical data and the virtual trial.

\begin{tabular}{lcc}
\hline Whole cohort statistics & Clinical Data & Virtual trial \\
\hline Number of episodes: & 7 & 7 \\
Total hours: & 359 hours & 359 hours \\
Number of BG measurements: & 239 & 203 \\
BG median [IQR] (mmol/L): & $8.30[6.32-10.00]$ & $6.80[5.50-8.07]$ \\
BG mean (geometric) (mmol/L): & 7.86 & 6.64 \\
BG Standard Deviation (geometric) (mmol/L): & 1.39 & 1.35 \\
\% BG within 4.0 - 6.1 mmol/L: & 23.85 & 38.91 \\
\% BG within 4.4 - 7.0 mmol/L: & 29.71 & 47.78 \\
\% BG within 4.4 - 8.0 mmol/L: & 43.93 & 66.50 \\
\% BG within 8.0 - 10.0 mmol/L: & 28.03 & 18.22 \\
\% BG >10.0 mmol/L: & 23.85 & 7.88 \\
\% BG <4.4 mmol/L: & 5.02 & 8.37 \\
\% BG <4.0 mmol/L: & 1.67 & 5.42 \\
\% BG <2.22 mmol/L: & 0.42 & 0 \\
Number of patients <2.22 mmol/L: & 1 & 0 \\
Median insulin rate [IQR] (U/hr): & $2.0[1.0-3.8]$ & $3.0[1.5-6.0]$ \\
Median glucose rate [IQR] (g/hour): & $6.0[4.9-8.3]$ & $5.5[3.9-6.6]$ \\
\hline
\end{tabular}

Clinical results are provided for all individual episodes in Table 3 and Figure 3. Overall, these results indicate that these specific patients were particularly insulin resistant. In addition, the pilot trial length was not sufficient to achieve consistently high percentages of BG levels in a tight band around the target where resistance and variability decline significantly after 48-72 hours. In this trial, only one episode exceeds this length (episode 2c).

\section{Discussion}

The objective of this pilot trial is to look at the initial assessment of performance, safety and compliance of STAR in a Malaysian ICU. This trial was started off using a benchmarked BG target range of $4.4-8.0 \mathrm{mmol} / \mathrm{L}$. Overall results suggest that the protocol can be considered to be used in Malaysian intensive care. However, the clinical performance assessment in Table 2 where a significant $23.85 \%$ of BG level above $10.0 \mathrm{mmol} / \mathrm{L}$ and $28.03 \%$ of $\mathrm{BG}$ level within $8.0-10 \mathrm{mmol} / \mathrm{L}$ raises the question of whether to put a different target range for Malaysian patients. Results from virtual trial shows percentage of light hypoglycaemia is above $5 \%$ ( $8.37 \%$ for BG $<4.4 \mathrm{mmol} / \mathrm{L}$ and $5.42 \%$ for $<4.0$ $\mathrm{mmol} / \mathrm{L})$ also suggest the same proposition. 

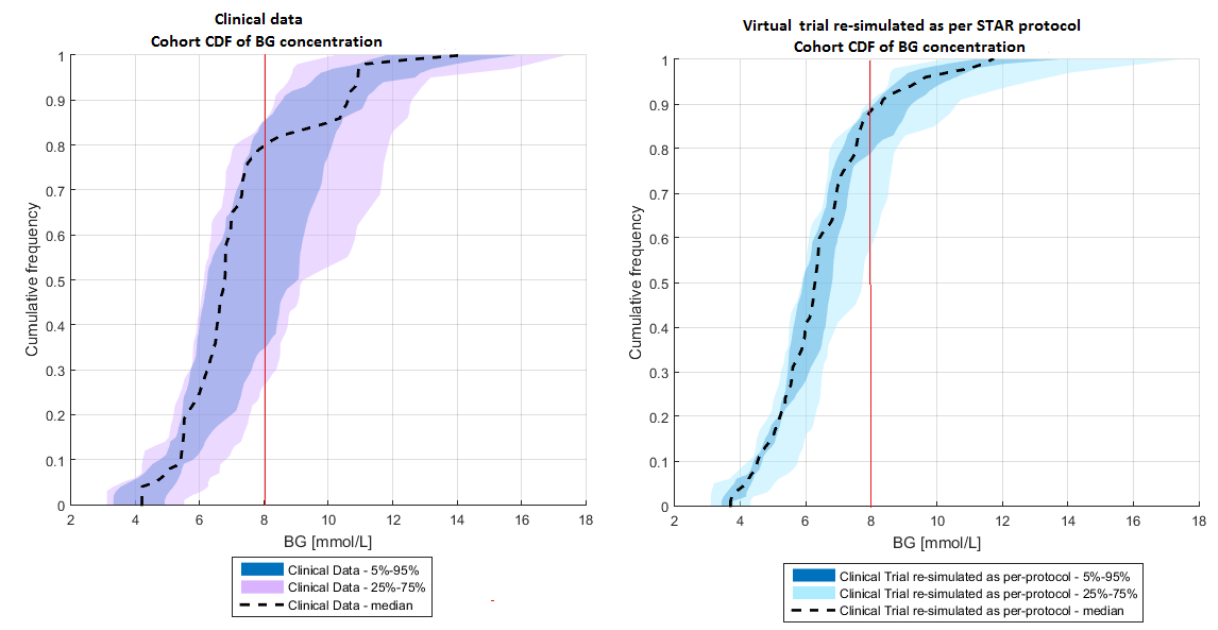

Fig. 2: Median, 25-75\% and 5-95\% intervals of per-patient BG Cumulative Distribution Functions (CDFs) defined on whole cohort.

This pilot clinical trial is the first attempt to use STAR protocol in a Malaysian ICU. Another important result is one patient episode with severe hypoglycemia $(\mathrm{BG}<2.22 \mathrm{mmol} / \mathrm{L})$. Figure $4 \mathrm{a}$ shows episode $2 \mathrm{~b}$ profile with hypoglycemia. The results for this episode $2 \mathrm{~b}$ were re-simulated and the new outcome is shown in Figure $4 \mathrm{~b}$. It demonstrates no hypoglycemia. In fact, this patient has an overall low insulin sensitivity. He was admitted with polytrauma secondary to motorvehicle accident. One main difference comes from the number of BG measurement (26 in clinical trial vs. 23 in simulation) which modifies iterative forecasting of insulin and nutrition input towards patient. As a result, clinical patient has higher BG measurement even though still in target range and a rise in insulin

Table 3: Clinical results for each patient.

\begin{tabular}{|c|c|c|c|c|c|c|c|c|c|c|c|c|c|}
\hline \multirow{2}{*}{ Patient } & BG & \multirow{2}{*}{$\begin{array}{c}\mathrm{BG} \\
\text { mean } \\
(\mathrm{mmol} / \mathrm{L})\end{array}$} & \multirow{2}{*}{$\begin{array}{c}\text { BG } \\
\text { StDev } \\
(\mathrm{mmol} / \mathrm{L})\end{array}$} & \multirow{2}{*}{$\begin{array}{c}\% \mathrm{BG} \\
\text { within } \\
4.4-6.1 \\
\mathrm{mmol} / \mathrm{L}\end{array}$} & \multirow{2}{*}{$\begin{array}{c}\% \mathrm{BG} \\
\text { within } \\
4.4-7.0 \\
\mathrm{mmol} / \mathrm{L}\end{array}$} & \multirow{2}{*}{\begin{tabular}{|c|}
$\% \mathrm{BG}$ \\
within \\
$8.0-10.0$ \\
$\mathrm{mmol} / \mathrm{L}$
\end{tabular}} & \multirow{2}{*}{$\begin{array}{c}\% \mathrm{BG} \\
>10.0 \\
\mathrm{mmol} / \mathrm{L}\end{array}$} & \multirow{2}{*}{$\mid \begin{array}{c}\% \mathrm{BG} \\
<4.4 \\
\mathrm{mmol} / \mathrm{L}\end{array}$} & \multirow{2}{*}{$\begin{array}{c}\% \mathrm{BG} \\
<4.0 \\
\mathrm{mmol} / \mathrm{L}\end{array}$} & \multirow{2}{*}{$\begin{array}{c}\% \mathrm{BG} \\
<2.22 \\
\mathrm{mmol} / \mathrm{L}\end{array}$} & Median & \multirow{2}{*}{$\begin{array}{l}\text { Max } \\
\text { nsulin } \\
\text { rate } \\
\text { (U/hr): }\end{array}$} & \multirow{2}{*}{\begin{tabular}{|c}
$\begin{array}{c}\text { Median } \\
\text { dextrose }\end{array}$ \\
rate \\
{$[\mathrm{IQR}]$} \\
(g/hour):
\end{tabular}} \\
\hline & $\begin{array}{c}\text { median }[\mathrm{IQR}] \\
(\mathrm{mmol} / \mathrm{L}):\end{array}$ & & & & & & & & & & \begin{tabular}{|c|} 
insulin rate \\
{$[\mathrm{IQR}](\mathrm{U} / \mathrm{hr}):$}
\end{tabular} & & \\
\hline \multirow{2}{*}{ 1a } & 6. & \multirow[b]{2}{*}{6.52} & \multirow[b]{2}{*}{1.33} & \multirow[b]{2}{*}{41.18} & \multirow{2}{*}{61.76} & \multirow{2}{*}{14.71} & \multirow[b]{2}{*}{5.88} & \multirow{2}{*}{5.88} & \multirow[b]{2}{*}{2.94} & & 1 & & $\frac{18 / 10}{3.8}$ \\
\hline & 5.4 & & & & & & & & & & $0.6-1$. & & $|3.8-5.7|$ \\
\hline $2 \mathrm{a}$ & $\begin{array}{c}8.8 \\
{[7.9-10 .}\end{array}$ & 8.52 & 1.27 & 11.76 & 17.65 & 43.14 & 29.41 & 1.96 & & & $\frac{2}{[1.2-3.0]}$ & 8.6 & $\frac{8.3}{[8.3-11.4]}$ \\
\hline $2 \mathrm{~b}$ & \begin{tabular}{|c|}
9.9 \\
{$[7.3-12.2$} \\
\end{tabular} & 8.92 & 1.59 & 10.71 & 14.29 & 17.86 & 46.43 & 7.14 & 3.57 & 3.57 & $\frac{2.9}{2.0-6.3}$ & 8 & \begin{tabular}{|c|}
6.3 \\
{$[5.7-8.9]$}
\end{tabular} \\
\hline 3 & \begin{tabular}{|c|}
7 \\
{$[5.8-9.4$}
\end{tabular} & 7.34 & 1.49 & 29.17 & & 4.167 & 25 & 16.67 & 0 & 0 & $\frac{2.7}{[1.1-4.2]}$ & 10 & \begin{tabular}{|c|}
2.1 \\
{$[0.7-4.9]$} \\
\end{tabular} \\
\hline $1 \mathrm{~b}$ & $\frac{[0.0}{6.7}$ & 6.46 & 1.35 & 29.63 & 48.15 & 18.52 & 3.7 & 7.41 & 7.41 & 0 & $\frac{1}{[0.2-1.4]}$ & 4 & $\begin{array}{c}5.1 \\
{[5.1-5.1]} \\
\end{array}$ \\
\hline $2 \mathrm{c}$ & $\frac{9.5}{[8.5-10.2]}$ & 9.05 & 1.25 & 7.02 & 8.77 & 47.37 & 31.58 & 1.75 & 0 & 0 & $\frac{4.3}{[2.5-6.0]}$ & 10 & \begin{tabular}{|c|}
8.3 \\
{$[6.4-8.3]$} \\
\end{tabular} \\
\hline 4 & $\begin{array}{c}6.4 \\
{[5.7-7.8]}\end{array}$ & 6.93 & 1.29 & 38.89 & 55.56 & 11.11 & 11.11 & 0 & 0 & 0 & $\begin{array}{c}1.5 \\
1.0-2.0]\end{array}$ & 4 & \begin{tabular}{|c|}
4.9 \\
$4.9-4.9]$ \\
\end{tabular} \\
\hline
\end{tabular}




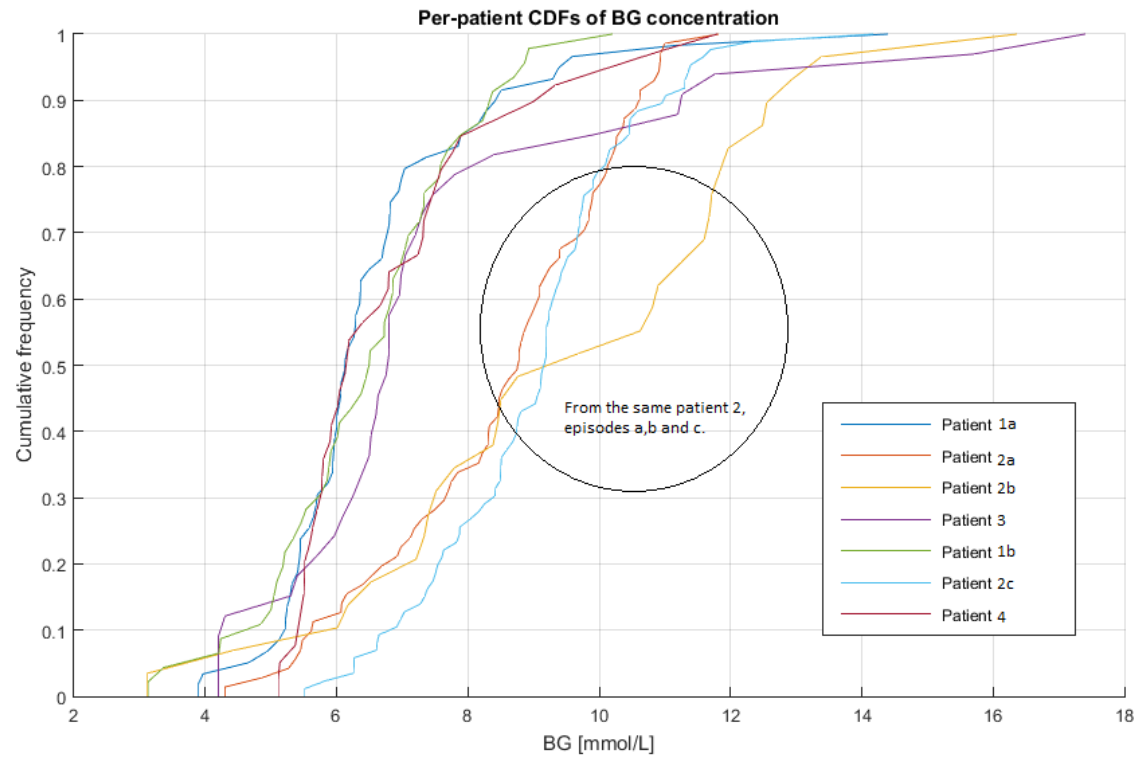

Fig. 3: Per-patient CDFs of BG concentration.

sensitivity is recorded before the hypoglycemia is detected. More differences can be seen on the proposition for insulin and nutrition input. These differences question the nurses' compliance during clinical implementation.

\section{Conclusion}

This pilot study shows the results of our inital attempt of using Stochastic TARgeted (STAR) protocol in the intensive care unit, IIUM hospital. We demonstrated that this approach was able to provide a good blood glucose control among critically ill Malaysian patients and was adaptable according to patients' clinical condition. We have identified specific issues that warrant modification of the protocol in order to improve its performance, if it is to be used in future trials. This is to ensure its safety and efficiency in achieving good glycemic control in Malaysian ICU population.

\section{Acknowledgement}

The authors thankfully acknowledge IIUM for their support and provision of data for the pilot study. The authors also acknowledge Ministry of Higher Education (MOHE), BOLD Scheme and UNITEN for their support on the ongoing Research. 

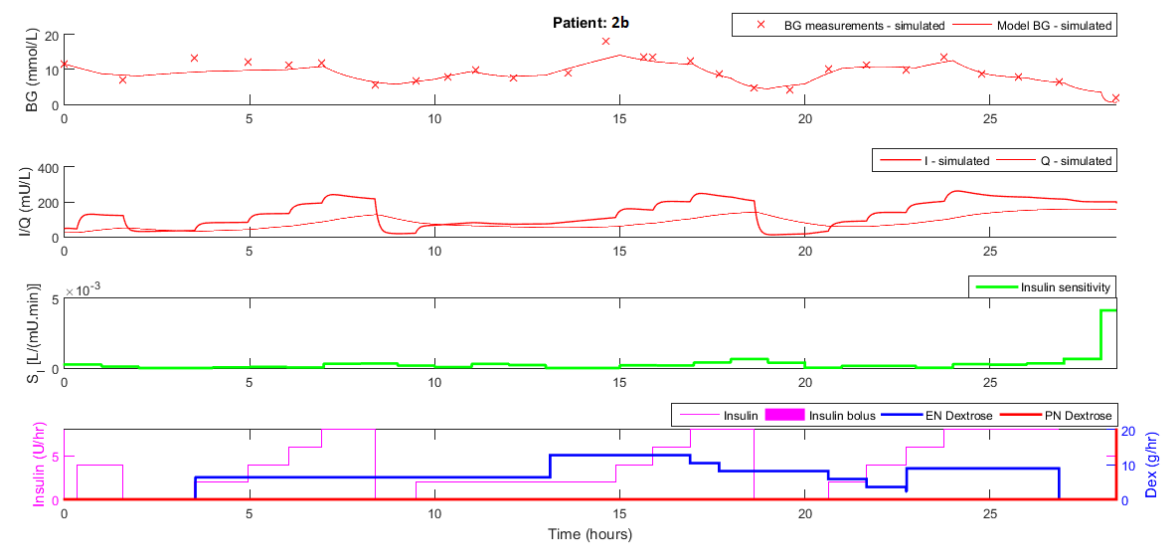

(a) Clinical results
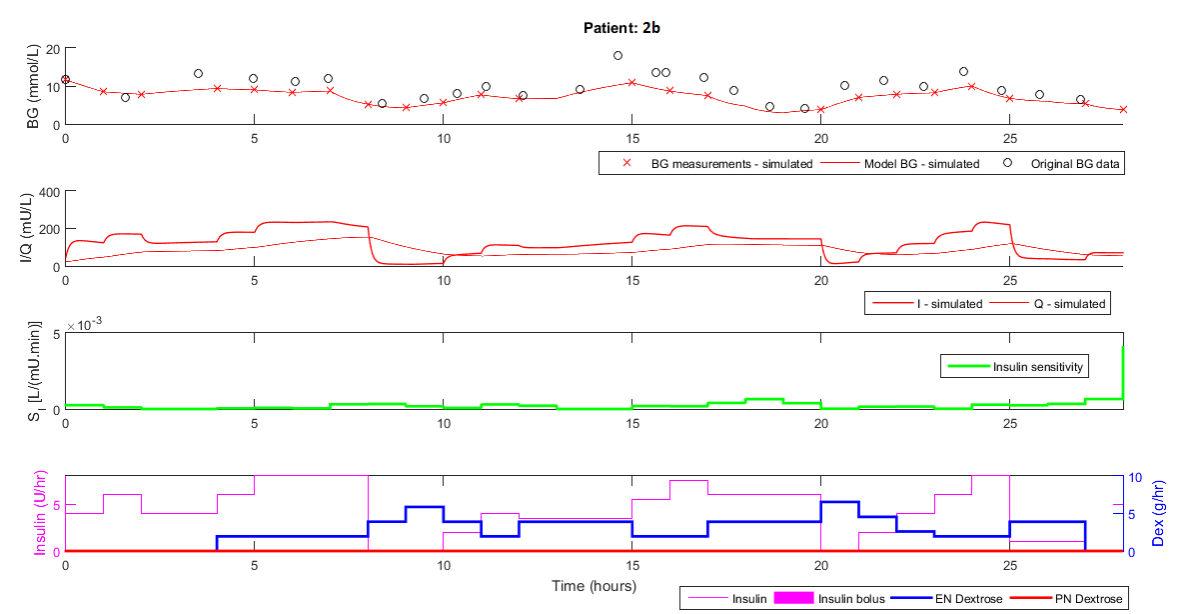

(b) Clinical data re-simulated with STAR protocol

Fig. 4: Patient 2b profiles. 


\section{References}

[1] Marik, P. E., \& Raghavan, M. : Stress-hyperglycemia, insulin and immunomodulation in sepsis. Intensive care medicine, 30(5), 748-756 (2004).

[2] McCowen, K. C., Malhotra, A., \& Bistrian, B. R. : Stress-induced hyperglycemia. Critical care clinics, 17(1), 107-124 (2001).

[3] Ellahham, S.: Insulin therapy in critically ill patients. Vascular health and risk management, 6, 1089 (2010).

[4] Dungan, K. M., Braithwaite, S. S., \& Preiser, J. C.: Stress hyperglycaemia. The Lancet, 373(9677), 1798-1807 (2009).

[5] Bistrian, B. R.: Hyperglycemia and infection: which is the chicken and which is the egg?. Journal of Parenteral and Enteral Nutrition, 25(4), 180-181 (2001).

[6] Capes, S. E., Hunt, D., Malmberg, K., \& Gerstein, H. C.: Stress hyperglycaemia and increased risk of death after myocardial infarction in patients with and without diabetes: a systematic overview. The Lancet, 355(9206), 773-778 (2000).

[7] Van den Berghe, G., Wouters, P. J., Bouillon, R., Weekers, F., Verwaest, C., Schetz, M., Vlasselaers, D., Ferdinande, P., \& Lauwers, P.: Outcome benefit of intensive insulin therapy in the critically ill: insulin dose versus glycemic control. Critical care medicine, 31(2), 359-366 (2003).

[8] Krinsley, J. S.: Glycemic variability: a strong independent predictor of mortality in critically ill patients. Critical care medicine, 36(11), 3008-3013 (2008).

[9] Chase, J., Shaw, G., Le Compte, A., Lonergan, T., Willacy, M., Wong, X. W., Lin, J., Lotz, T., Lee, D., \& Hann, C.: Implementation and evaluation of the SPRINT protocol for tight glycaemic control in critically ill patients: a clinical practice change. Critical care, 12(2), p.R49 (2008).

[10] Brunkhorst, F.M., Engel, C., Bloos, F., Meier-Hellmann, A., Ragaller, M., Weiler, N., Moerer, O., Gruendling, M., Oppert, M., Grond, S., \& Olthoff, D. Intensive insulin therapy and pentastarch resuscitation in severe sepsis. New England Journal of Medicine, 358(2), pp.125-139 (2008).

[11] Nice-Sugar Study Investigators.: Intensive versus conventional glucose control in critically ill patients. N Engl J Med, 2009(360), pp.1283-1297 (2009).

[12] Marik, P. E., \& Preiser, J. C. Toward understanding tight glycemic control in the ICU: a systematic review and metaanalysis. CHEST Journal, 137(3), 544-551 (2010).

[13] Uyttendaele, V., Dickson, J.L., Shaw, G.M., Desaive, T., \& Chase, J.G.: Untangling glycaemia and mortality in critical care. Critical Care, 21(1), p.152 (2017).

[14] Lin, J., Razak, N. N., Pretty, C. G., Le Compte, A., Docherty, P., Parente, J. D., \& Chase, J. G.: A physiological Intensive Control Insulin-NutritionGlucose (ICING) model validated in critically ill patients. Computer methods and programs in biomedicine, 102(2), 192-205 (2011). 
[15] Dickson, J.L., Stewart, K.W., Pretty, C.G., Flechet, M., Desaive, T., Penning, S., Lambermont, B.C., Benyo, B., Shaw, G.M. and Chase, G., 2017. Generalisability of a Virtual Trials Method for Glycaemic Control in Intensive Care. IEEE Transactions on Biomedical Engineering.

[16] Fisk, L. M., Le Compte, A. J., Shaw, G. M., Penning, S., Desaive, T., \& Chase, J. G.: STAR development and protocol comparison. IEEE Transactions on Biomedical Engineering, 59(12), 3357-3364 (2012).

[17] Evans, A., Shaw, G. M., Le Compte, A., Tan, C. S., Ward, L., Steel, J., Pretty, C. G., Pfeifer, L., Penning, S., Suhaimi, F., \& Signal, M.: Pilot proof of concept clinical trials of Stochastic Targeted (STAR) glycemic control. Annals of intensive care, 1(1), 38 (2011).

[18] Chase, J. G., Suhaimi, F., Penning, S., Preiser, J. C., Le Compte, A. J., Lin, J., Pretty, C. G., Shaw, G. M., Moorhead, K. T., \& Desaive, T. (2010). Validation of a model-based virtual trials method for tight glycemic control in intensive care. Biomedical engineering online, 9(1), 84.

[19] Stewart, K. W., Pretty, C. G., Tomlinson, H., Thomas, F. L., Homlok, J., Noémi, S. N., Illyés, A., Shaw, G. M., \& Chase, J. G. : Safety, efficacy and clinical generalization of the STAR protocol: a retrospective analysis. Annals of intensive care, 6(1), 24 (2016). 